\title{
Factors associated with urinary incontinence in women
}

\author{
J. W. G. YARNELL, G. J. VOYLE, P. M. SWEETNAM, AND JANET MILBANK \\ From the Medical Research Council Epidemiology Unit; Cardiff \\ C. J. RICHARDS AND T. P. STEPHENSON \\ From the Departments of Gynaecology and Urology, Welsh National School of Medicine, Cardiff
}

SUMmaRY Possible aetiological factors for urinary incontinence were examined in a prevalence study among a random sample of 1000 women aged 18 and over. Infective factors were not markedly associated with incontinence but mechanical factors such as parity and obesity were. No association was found, however, between a history of perineal damage at childbirth and incontinence. Women with incontinence had on average a higher score for a 'neuroticism' trait elicited by questionnaire than women without the disorder.

Little is known with certainty about the causes of urinary incontinence in women but many associated and predisposing factors have been described. ${ }^{1}$ Simple stress incontinence is said to be associated commonly with vaginal prolapse ${ }^{2}$ but factors related to urgency-associated incontinence are numerous. ${ }^{3}$ In the present study a questionnaire was administered by trained interviewers to a random sample of women from the community. The prevalence and severity of the disorder has been reported previously ${ }^{4}$ and in the present paper we report the findings relating to the aetiological hypotheses which were tested by the study.

\section{Methods}

A random sample of 1140 women was drawn from the electoral register for a small town in South Wales. Five trained women interviewers questioned the subjects in their homes. The questionnaire* included sections on medical history and urinary symptomatology. Three types of incontinence were defined: urge, stress, and complex (urge and stress types combined). All results relate to episodes of incontinence which occurred during a 12-month period before the interview. The detailed methodology has been described previously. ${ }^{4}$ Urine samples were obtained at the home visits by an aseptic procedure. Asymptomatic bacteriuria was detected by the use of Till-u-Test dip slides. A brief psychometric questionnaire was used to evaluate the trait 'neuroticism', based on nine questions from the

*Copies of the complete questionnaire are available from the authors.
Cornell Medical Index. This has been validated elsewhere. ${ }^{5}$ All tests of statistical significance were carried out on two groups only: 'no incontinence' versus 'all incontinence'.

\section{Results}

After the exclusion of subjects who had died or left the area the final sample eligible for inclusion in the study was 1058 . One thousand women (95\%) were interviewed in full and $951(90 \%)$ each provided a urine sample.

Four groups of factors may cause urinary incontinence: infective, mechanical, neurological, and hormonal. Specific hypotheses under test are summarised under these four headings.

Infective factors Previous attacks of cystitis (that is, any previous episodes of cystitis or bladder infection) were found to be significantly associated with incontinence; the largest contribution was from complex incontinence. A similar but weaker relationship was found with previous vaginal discharge. Neither a previous history of pyelitis nor of asymptomatic bacteriuria was significantly associated with incontinence. These findings occurred in all age groups. Table 1 gives a summary of these results in the combined age groups.

Mechanical factors Those likely to be associated with raised intra-abdominal pressure and lower-than-average perineal tone were examined (Table 2). Obesity, which was determined by the use 
Table 1 Infective factors by type of incontinence

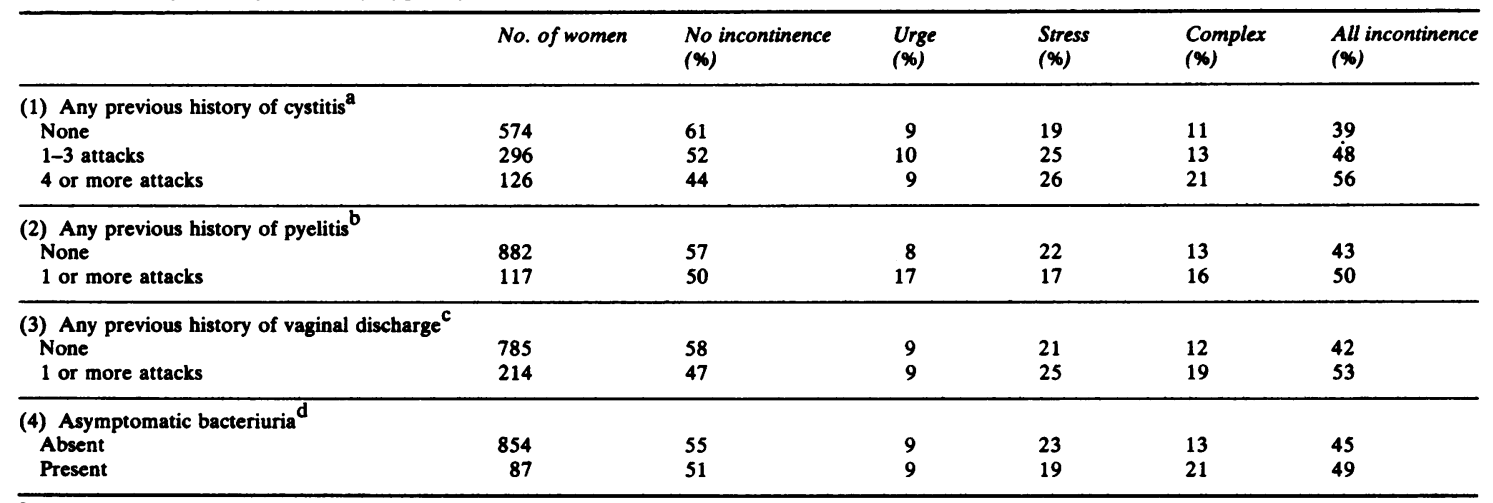

a Previous history of cystitis not recorded for four subjects: $x^{2}=15.1 \quad 2$ df $p<0.01$

${ }^{b}$ Previous history of pyelitis not recorded for four subjects: $x^{2}=1.91 \mathrm{df}$ NS.

${ }^{c}$ Previous vaginal discharge not recorded for one subject: $x^{2}=8.2 \quad 1$ df $p<0.005$.

${ }^{d}$ Urine sample not obtained from 59 subjects: $x^{2}=0.7 \quad 1$ df NS.

Table 2 Mechanical factors by type of incontinence

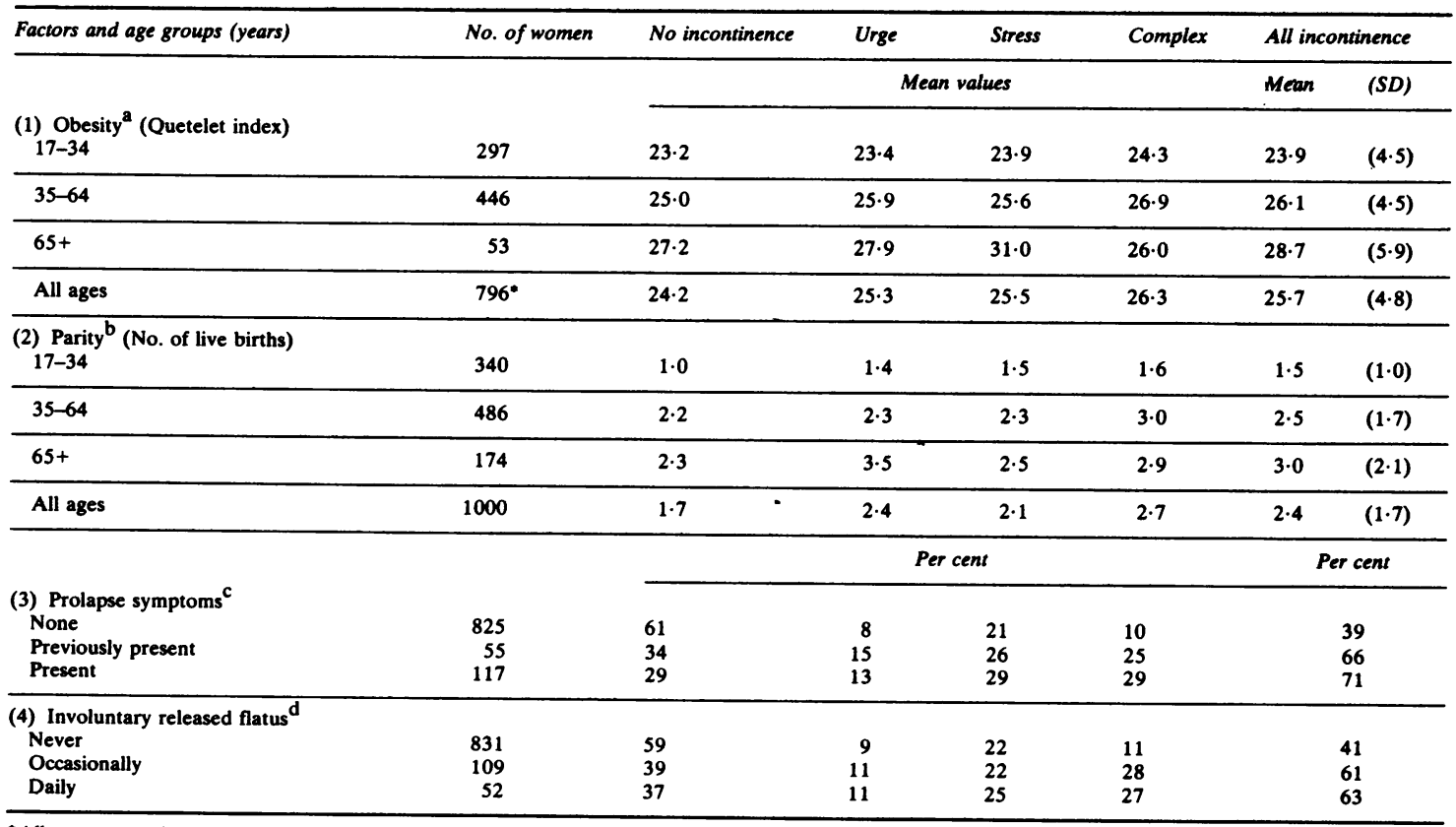

-All women aged under $70(n=894)$ were invited to participate in a further unrelated study in which weight and height were recorded.

a Analysis of covariance (age as covariate) $F=8.9 \quad p<0.01$

b Analysis of covariance (age as covariate) $F=24 \cdot 1 \quad p<0.001$

$x^{2}=23.7 \quad 2$ df $\quad p<0.001$

$d^{2}=51.6 \quad 2$ df $p<0.001$ 
of Quetelet's index (weight $(\mathrm{kg}) \div$ height $^{2}\left(\mathrm{~m}^{2}\right)$ ), was found to be associated with the presence of all types of incontinence. Parity was also markedly associated with the presence of incontinence.

Women were asked in simple language whether they had symptoms possibly related to a prolapse 'a feeling in the front passage of something coming down'. This question was placed towards the end of the questionnaire separately from the questions on incontinence. A group of women who had been treated for symptoms due to prolapse was also defined. Symptoms related to prolapse were found to be markedly associated with the presence of incontinence, in particular with urge and complex incontinence. Women were also asked about involuntary release of flatus and faeces. There were too few women reporting faecal incontinence to justify a separate analysis but involuntary loss of flatus was associated with the presence of incontinence, in particular with complex incontinence. Although not shown in Table 2, both symptoms (prolapse and loss of flatus) were associated with incontinence in all the age groups examined.

Women were also asked about injuries to the perineum sustained during labour. A history of perineal tear, episiotomy, forceps delivery, breech delivery, or caesarean section, was separately noted. Although such histories were common, none was found to be associated with the presence of incontinence. Smoking habit via the mechanism of cough may also be related to the presence of incontinence but in the present data only women who smoked 20 or more cigarettes a day reported incontinence more frequently than other groups; but only complex incontinence. Ex-smokers also showed this association (ex-smokers and smokers of 20 cigarettes a day reported complex incontinence in 17 and $21 \%$ of cases respectively: non-smokers and light smokers in 11 and $12 \%$ respectively).

Neurological factors One hypothesis tested was that women who reported current incontinence had a constitutional deficiency in the neurological reflex mechanism that ensures continence. Women were asked at what age they were dry at night as an index of completed bladder training (Table 3). These results indicated a statistically significant trend, particularly among those who were dry at night only at the age of 10 or over, towards an association between late bladder training and subsequent incontinence.

Women were asked about their use of prescribed drugs, and we examined the influence of drugs acting on the central nervous system (principally psycholeptics) and on the cardiovascular system (principally diuretics). As expected, both psycholeptics and diuretics were associated with urinary incontinence in women aged 70 or over-psycholeptic use by $19 \%$ of women who did not report incontinence and $30 \%$ of those who did. For diuretics the comparable figures were $17 \%$ and $32 \%$ respectively. With the exception of the youngest age group, 17-29, in which psycholeptic drugs were taken more often by women who reported incontinence (18\%) than by those who did not report it $(3 \%)$, no other associations between drug usage and incontinence were noted.

A brief psychometric questionnaire was used towards the end of each interview and the trait 'neuroticism' was assessed on a continuous scale rated from 0 (absence of the trait) to 9 . Women who reported incontinence tended to have higher than average scores; this effect was least for stress

Table 3 Distribution by age at completion of bladder training and presence or absence of incontinence

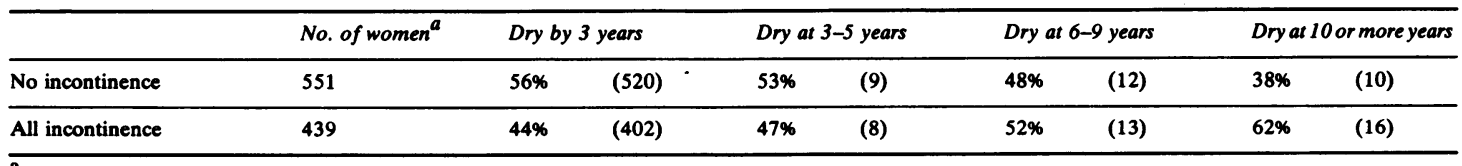

${ }^{a}$ Bladder training not recorded for 10 subjects

$x^{2}$ for trend $=3.9 \quad 1 \mathrm{df} p<0.05$

Table 4 Distribution of neuroticism score by age group and type of incontinence

\begin{tabular}{|c|c|c|c|c|c|c|}
\hline \multirow{3}{*}{$\begin{array}{l}\text { Age groups (years) } \\
17-34\end{array}$} & \multirow{3}{*}{$\begin{array}{l}\text { No incontinerice } \\
1.6\end{array}$} & \multirow{3}{*}{$\begin{array}{c}\text { Urge } \\
3 \cdot 0\end{array}$} & \multirow{2}{*}{$\frac{\text { Stress }}{\text { alues }}$} & \multirow[t]{2}{*}{ Complex } & \multicolumn{2}{|c|}{ All incontinence } \\
\hline & & & & & Mean & $(S D)$ \\
\hline & & & 2.0 & 3.0 & 2.4 & $(2 \cdot 2)$ \\
\hline $35-64$ & $2 \cdot 2$ & 2.6 & 2.4 & $3 \cdot 2$ & 2.7 & $(2 \cdot 2)$ \\
\hline $65+$ & 1.9 & 2.9 & 2.4 & 3.4 & 2.9 & $(2 \cdot 1)$ \\
\hline All ages & 1.9 & 2.7 & $2 \cdot 3$ & $3 \cdot 2$ & 2.7 & $(2 \cdot 2)$ \\
\hline
\end{tabular}

Analysis of covariance (age as covariate) $\mathrm{F}=31.7 \quad \mathrm{p}<0.001$ 
Table 5 Distribution by episodes of dysuria symptoms and type of incontinence

\begin{tabular}{|c|c|c|c|c|c|c|}
\hline & No. of women ${ }^{a}$ & $\begin{array}{l}\text { No incontinence } \\
(\%)\end{array}$ & $\begin{array}{l}\text { Urge } \\
(\%)\end{array}$ & $\begin{array}{l}\text { Stress } \\
(\%)\end{array}$ & $\begin{array}{l}\text { Complex } \\
(\%)\end{array}$ & $\begin{array}{l}\text { All incontinence } \\
\text { (\%) }\end{array}$ \\
\hline No episode of dysuria in previous 12 months & 824 & 59 & 8 & 22 & 11 & 41 \\
\hline 1-3 episodes in previous 12 months & 98 & 53 & 14 & 26 & 7 & 47 \\
\hline $4+$ episodes in previous 12 months & 35 & 23 & 29 & 17 & 31 & 77 \\
\hline Dysuria only with menstruation & 31 & 20 & 0 & 19 & 61 & 80 \\
\hline
\end{tabular}

${ }^{a}$ Dysuria not recorded for 12 subjects

${ }^{b} \chi^{2}=36.0 \quad 3$ df $p<0.001$

incontinence, more pronounced for urge incontinence, and strongest for complex incontinence. Since the neuroticism scores tended to be higher in the middle-aged and older age groups, the results refer to three age groups (Table 4).

Hormonal factors Two hypotheses were tested. Firstly, in order to investigate the association between menopausal changes and incontinence, women were asked at what age their menopause began and also whether it was artificially induced. The age of onset of the menopause ranged from 35 to 55 and no association was found between early age of onset or artificial induction of menopause and incontinence. Secondly, women who were still menstruating were asked about the symptom of dysuria and particularly about dysuria associated with menstruation. To our surprise, there was a marked association between complex incontinence and dysuria associated with menstruation. These results are shown in Table 5 and it should be noted that all rows are mutually exclusive.

Symptoms associated with particular types of incontinence Women were asked how many hours they could go during the day without passing urine. Women who were incontinent reported that they had to pass urine more often on average during the day than those who were not incontinent. This phenomenon was least marked for stress incontinence and most pronounced for complex incontinence (Table 6). A similar phenomenon was noted in response to a question about nocturnal frequency. The effect of age is also clearly shown by these results (Table 6).

The remaining symptoms were reported rather infrequently but serve to illustrate possible physiological differences between the types of incontinence. The symptoms of residual urine, straining, and restricted flow all tended to occur more often in women reporting urge and complex incontinence; there was a marked deficiency of such cases in women reporting stress incontinence (Table 6).

\section{Discussion}

The present results indicate that urinary incontinence is a disorder associated with many predisposing factors and it is clearly not possible to isolate any one as a major factor associated with any particular type of incontinence. One assumption on which the present analyses rest is that each type of incontinence represents a spectrum of symptoms from the minor physiological to the major pathological. The prevalence and severity of significant incontinence has been estimated previously ${ }^{4}$ and the overall prevalence of significant incontinence was estimated to be only $5 \%$. The present data were re-examined incorporating a severity classification into the analysis; the result of this was to increase substantially the strength of the associations between the various factors and severe incontinence (occurring weekly or more frequently). The associations were most markedly increased with mechanical factors such as parity and obesity.

Although certain infective factors (previous cystitis and previous vaginal discharge) were found to be significantly associated with incontinence, the associations were weak (Table 1). All significant associations, however, occurred in all age groups examined. Both asymptomatic bacteriuria ${ }^{6}$ and complex incontinence ${ }^{4}$ are more common in the elderly but we did not find a significant association between these factors. In nulliparous young women Wollin ${ }^{7}$ suggested that bacteriuria and incontinence were associated. However, in our data the prevalence of asymptomatic bacteriuria was much lower than that in Wollin's sample and we found no association in young women.

Mechanical factors, however, appear to be more closely associated with the presence of incontinence and, in general, their effect is independent of age (Table 2). Obesity and parity tend to be associated with incontinence and parity with urge and complex incontinence in particular. This would appear to support the view that incontinence of all types is associated with inadequate perineal tone, principally that of the levatore ani, and also that parity is of far 
Table 6 Distribution by symptoms and type of incontinence

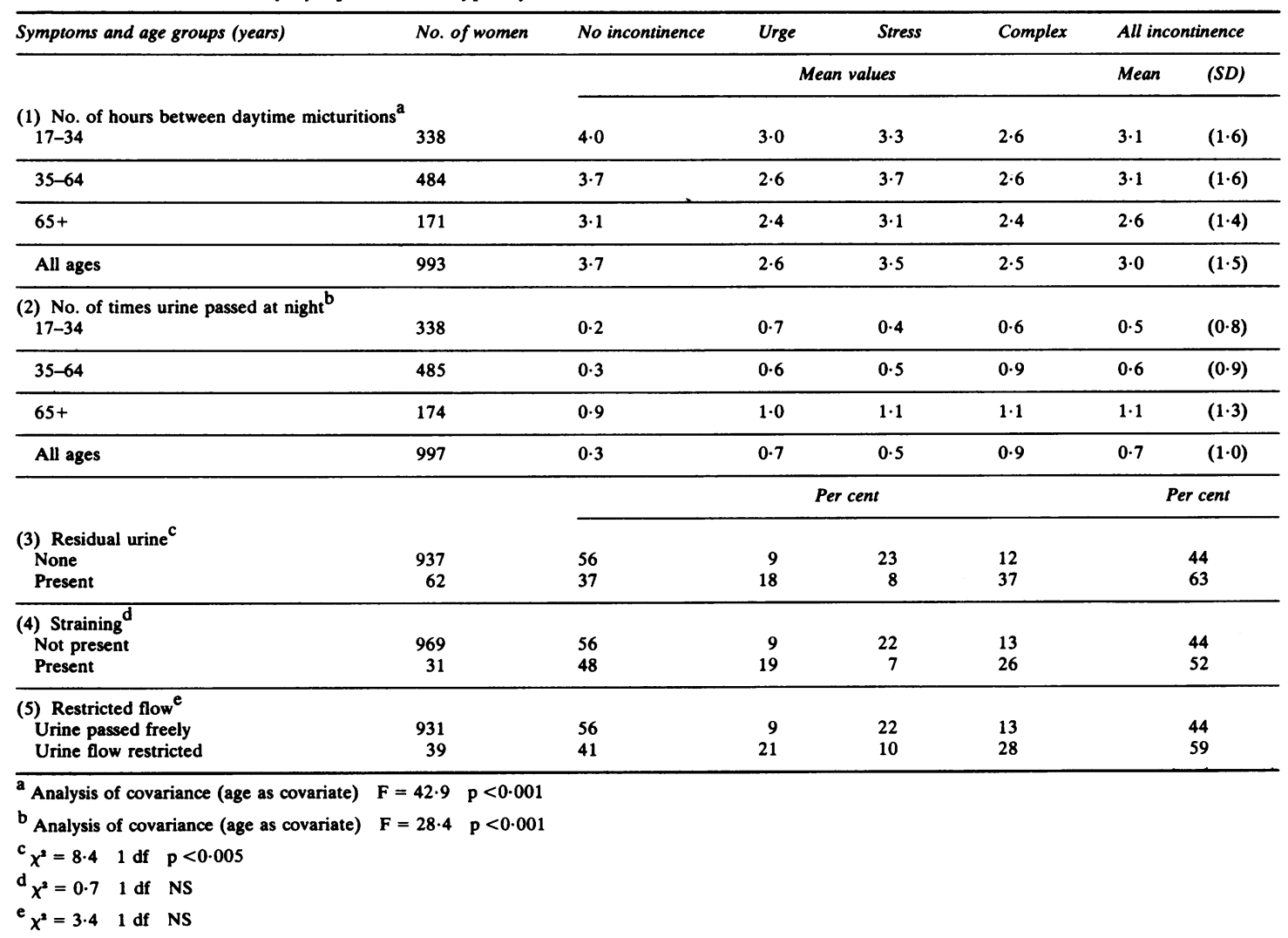

more importance than perineal damage associated with individual births. This would seem to provide some encouragement for the use of an intensive régime of pelvic floor exercises as a first-line therapy for the disorder. The role of this therapy has been reviewed by Isaacs. ${ }^{8}$

According to a comprehensive classification of incontinence based on clinical experience Green ${ }^{9}$ suggests that the only common form of neurologically-associated incontinence is 'detrusor dyssynergia' or unstable bladder. He estimates that $10 \%$ of all patients with incontinence have this functional entity. Psychogenic incontinence (incontinence comparable to enuresis of childhood) Green $^{9}$ states to be extremely rare, but Table 3 indicates that a significant proportion of women reported enuresis after the age of $10(26$ or $2.6 \%)$ and this was more commonly reported by incontinent women. However, this result may be due to recall bias; which is an inevitable possibility in a retrospective investigation. The use of drugs acting on the central nervous system was more common among a younger group of incontinent women and also in the elderly, but no cause-and-effect relationship can be assumed. Similarly, the marked association between neuroticism and incontinence cannot necessarily be judged to be causally related, since the former may follow as a consequence of the latter. However, a causal association may be a plausible possibility if linked via some neurological mechanism.

In spite of the common clinical experience of an association between the menopause and urinary symptoms ${ }^{10}$ no relation was found between age of onset of the menopause and incontinence. Since endogenous oestrogen levels fall to low levels after the menopause ${ }^{11}$ this does not seem to provide theoretical support for oestrogen replacement therapy for urinary incontinence in postmenopausal women. In premenopausal women, however, the association between complex incontinence and menstruation-associated dysuria does seem to merit further study. Hormonal changes can be profound during menstruation ${ }^{11}$ and the association with this symptom may lead to the identification of a subgroup of women who can be treated. 
We thank Professor A. W. Asscher for his support and assistance, and Ruth Mackenzie for her meticulous technical work.

Reprints from Dr. J. W. G. Yarnell, MRC Epidemiology Unit (South Wales), 4 Richmond Road, Cardiff CF2 3AS.

\section{References}

${ }^{1}$ Anonymous. Incontinent women. Lancet 1977; i: 521-2.

${ }^{2}$ Anonymous. Stress incontinence. $\mathrm{Br}$ Med J 1977; ii: 2-3.

${ }^{3}$ Edwards L. Incontinence of urine. In: Blandy J, ed. Urology. London: Academic Press, 1976: 687-733.

${ }^{4}$ Yarnell JWG, Voyle GJ, Richards CJ, Stephenson TP. The prevalence and severity of urinary incontinence in women.J Epidemiol Community Health 1981; 35: 71-4.
${ }^{5}$ Waters WE. Smoking and neuroticism. Br J Prev Soc Med 1971; 25: 162-4.

${ }^{6}$ Brocklehurst JC, Fry J, Griffiths LL, Kalton G. Urinary infection and symptoms of dysuria in women aged 45-64 years; their relevance to similar findings in the elderly. Age Ageing 1972; 1: 41-7.

${ }^{7}$ Wollin LH. Stress incontinence in young, healthy nulliparous female subjects. $J$ Urol 1969; 101: 545-9.

${ }^{8}$ Isaacs B. Preservation of continence. In: Willington FL, ed. Incontinence in the elderly. London: Academic Press, 1976: 245-51.

${ }^{y}$ Green TH. Urinary stress incontinence: pathophysiology, diagnosis and classification. In: Buschbaum $\mathrm{HJ}$, Schmidt $\mathrm{JD}$, eds. Gynecologic and obstetric urology. Philadelphia: WB Saunders, 1978: 162-88.

${ }^{10}$ Jequier AM. Urinary symptoms and total hysterectomy. Br J Urol 1976; 48: 437-41.

${ }^{11}$ Diem K, Lentner C. Scientific tables, 7th edn. Basle: Ciba-Geigy, 1970: 753-7. 